\title{
"Ex vivo comparative evaluation of efficacy of disinfecting ability of garlic oil, neem oil, clove oil and tulsi oil with autoclaving on endodontic K files, tested against aerobic bacteria"
}

\begin{abstract}
Aim: This study aims for comparative evaluation of efficacy of disinfecting ability of garlic oil, neem oil, clove oil and tulsi oil with autoclaving on endodontick files tested againstaerobic and anaerobic bacteria.

Materials and Methods: 50 endodontic K-file were used in oral cavity as sample size, which were immersed into 4 different herbal oils and were checked for its disinfecting ability with three different methods.

Results: In this study garlic oil is more effective against aerobic bacteria when compared to neem oil, clove oil and tulsi oil.

Conclusion: Garlic oil can be used as an alternative method to autoclave against aerobic bacteria but autoclave is a gold standard disinfecting method for sterilization.
\end{abstract}

Key word: file sterilization method, antibiotic properties of herbal oil, aerobic and anaerobic microorganism present in root canal infection.

\section{Introduction :}

Microorganisms induce a variety of infectious diseases in the human body. Infection control is a major topic of concern in medical and dental health care settings. Virtually, 700 bacterial species reside in the oral cavity of human beings with each individual harboring 100-200 species on an average.[1] Various studies proved that the presence of microbiota was a major determinant in endodontic infections, thus the success of endodontic treatment depends on the eradication of these microbes from the pulp chamber and root canals for that various endodontic instruments such as barbed broaches, reamers and files.[2]

Sterilization prevents the spread of infectious diseases for that various methods to sterilize the instruments are used such as dry heat sterilizer, autoclave, glass-bead sterilizer etc.Among them Autoclave is the gold standard method to sterilize endodontic files, but it has some disadvantages like it alters the physical properties of file.[3]

Phytodentistry has a connect with dentistry due to its properties, such as it does not affect physical properties of

\begin{tabular}{|l|l|}
\hline \multicolumn{2}{|c|}{ Access this article online } \\
\hline \multirow{2}{*}{$\begin{array}{l}\text { Website: } \\
\text { www.ujds.in }\end{array}$} & Quick Response Code \\
\hline $\begin{array}{l}\text { DOI: } \\
\text { https://doi.org/10.21276/ujds.2020.6.3.6 }\end{array}$ \\
\hline
\end{tabular}

instruments and microorganisms are unable to develop resistance against the agents used.[4]

Many studies showed the efficacy of garlic, neem, clove and tulsi oils against various microorganisms. Thus, the aim of this study was to evaluate the efficacy of disinfecting ability of garlic, neem, clove and tulsi oils against aerobic bacteria.

\section{Materials and Method:}

Institutional ethical approval was taken by college of dental sciences and hospital.

Sample distribution

${ }^{1}$ ISANI A., ${ }^{2}$ MASIH U., ${ }^{3}$ JOSHI K.

${ }^{1}$ Department of Pediatric and Preventive Dentistry, College of Dental Science, Amargadh, Bhavnagar, Gujarat.

${ }^{2}$ Department and co- guide, Department of Pediatric and Preventive Dentistry, College of Dental Science, Amargadh, Bhavnagar, Gujarat.

${ }^{3}$ Department of Microbiology, Government Medical College, Bhavnagar, Gujarat.

Address for Corresponding : Dr. Updesh Masih Department of Pediatric and Preventive Dentistry, College of Dental Science, Amargadh, Bhavnagar, Gujarat. Email: updesh_74@yahoo.com

Received : 15 August 2020, Published : 31 Dec. 2020

How to cite this article: Isani A., Masih U., \& Joshi K. (2021). Ex vivo comparative evaluation of efficacy of disinfecting ability of garlic oil, neem oil, clove oil and tulsi oil with autoclaving on endodontic $\mathrm{K}$ files, tested against aerobic bacteria. UNIVERSITY JOURNAL OF DENTALSCIENCES, 6(3). 
The present study was carried out on 10 \# K file. 10 files were taken as control group, and the remaining 40 files were divided into 4 groups of 10 files each in four different modes of oil during sterilization: garlic oil, neem oil, clove oil and tulsi oil.

\section{Process for file sterilization :}

$\mathrm{K}$ file of each group immersed into herbal oils for $5 \mathrm{~min}$. [Shown in fig: 1]

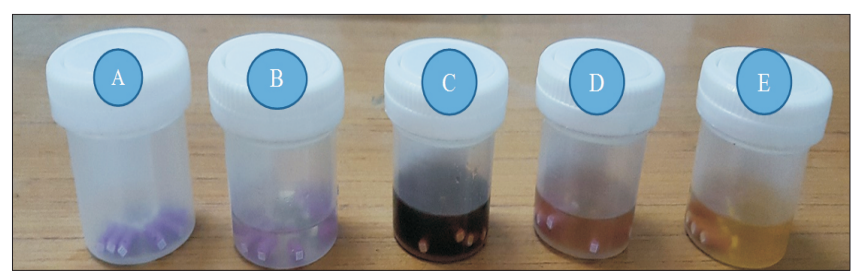

Figure: 1. A- Autoclaved, B-Clove Oil,C-Neem Oil, D-Tulsi Oil, E-Garlic

Which were checked for its disinfecting ability with three different methods as following

- Turbidity test

- Culture test

- Microscopic examination

\section{Turbidity test:}

Each file was immersed into peptone water test tube and left for 24 hours to check turbidity. [Shown in fig: 2]

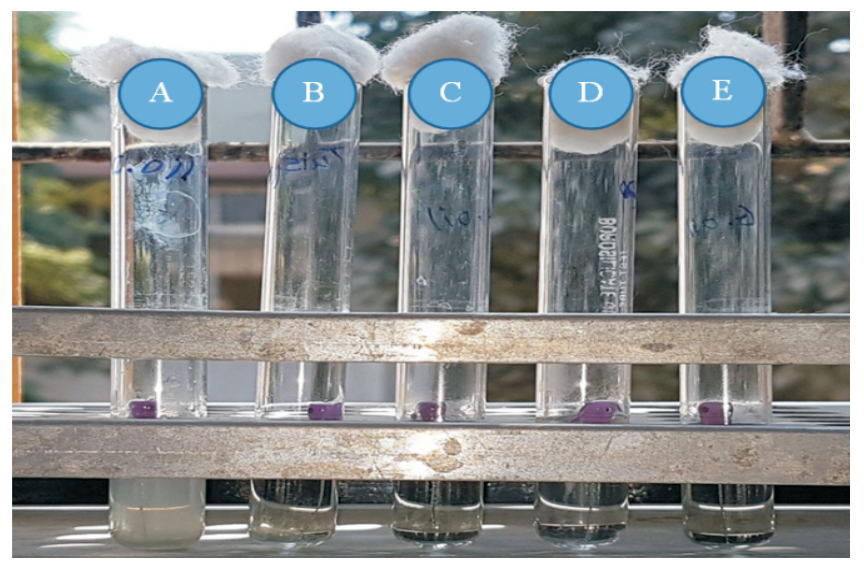

Figure 2. A- Clove oil, B-Tulsi oil, C-Neem oil, D-Autoclaved, E-Garlic oil

\section{Culture test}

In blood agar streaking method, using the sterile loupes, the inoculum from the test tube was streaked onto the blood agar fplate and checked for colony growth. [Shown in fig: 3]

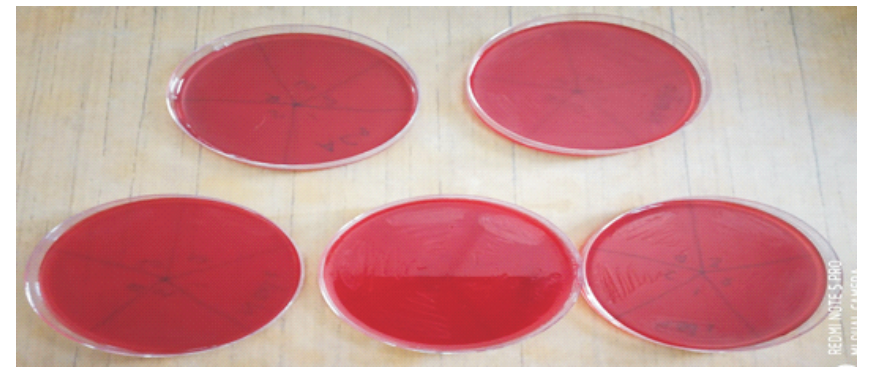

Figure 3. Blood agar culture for all the groups

\section{Microscopic examination}

In case of microscopic examination using Gram's stain, the standard strain was checked with respect to all disinfected files by the different methods. [Shown in fig: 4]

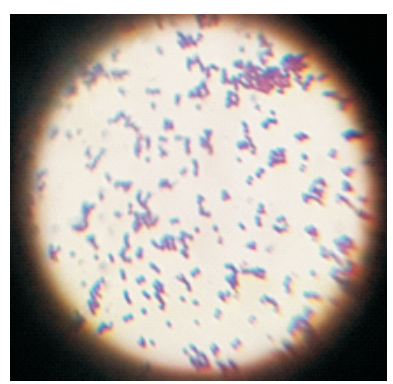

Tulsi oil showing gram positive cocci

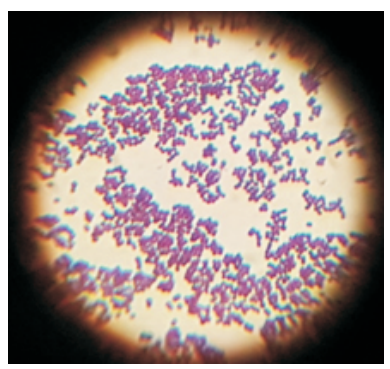

Clove oil showing gram positive cocci

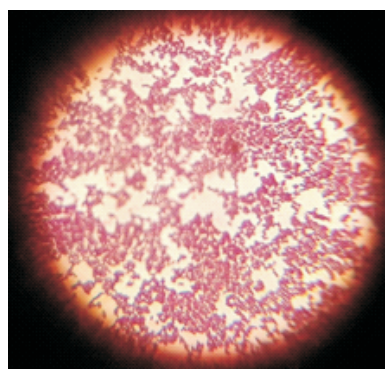

Neem oil showing gram positive cocci 


\section{Result:}

In present study, turbidity test was positive for clove oil,neem oil, tulsi oil and negative for garlic oil. In blood agar culture, microorganism growth was seen in clove oil, tulsi oil and neem oil and no growth was seen in garlic oil.In microscopic examination, gram positive cocci was seen in all three oil except garlic oil; in neem oilstaphylococcus aureuswas seen, in tulsi oil enterococcus species and klebsiella species was seenand in clove oil, enterococcus species was observed.

\section{Discussion:}

Root canal infection is a dynamic process with diverse microbes such as Gram-positive facultative cocci, lactobacilli, Fusobacteriumnucleatum, Actinomyces, Porphyromonasendodontalis, Porphyromonasgingivalis, E. coli, E. faecalis, and Candida, with Actinomyces which are dominating at various stages of disease process. [5]

Even though about 500 bacterial species are recognized as normal inhabitants of oral cavity, only 150 microbial species have been isolated from the infected root canals.[6] In the present study, all bacteria were chosen as the test microorganism.

In this study, garlic oil showed complete sterilization of all the samples of the microorganisms. The results were in agreement with the studies conducted by Hugar S. due to the garlic content Allicin (allyl-2-propenethiosulfinate) as it is the primary constituent associated with garlic's antimicrobial activity. (Matsuura, 1997; Lawson et al, 1990).[4,7]

Neem the versatile medicinal plant is the source of several compounds having diverse chemical structure and biological effects. [8]

Neem is been used extensively in Ayurveda, unani and homeopathic medicine and has become a wonder tree of modern medicine. [9]

Neem oil is extracted from the seed. It contains one seed, which in turn can have one or more kernels. It is produced by crushing and pressing the kernels and then by purifying the extract. Over many years the beneficial properties of neem have been recognised in Indian tradition. Each part of neem tree has some medicinal property. [10]
The is oprenoid group of the constituents of neem have antiinflammatory,[11,12] anti-bacterial,[13,14]anti-fungal[1516] and immunomodulatory properties [17] but in our study

Neem oil showed incomplete sterilization of the samples for tested organisms similar to Hugar Set al.[4] due to potential antimicrobial efficacy against microorganism is dependent on time duration according to Dikshita Ray Barua et al.[18]

Among the medicinal plants, aromatic herbs are a rich source of biologically active compounds useful both in agriculture and medicine.[19] Of these, Ocimumtenuiflorum, also known as Ocimumsanctum, Tulsi, or Holy Basil from the family Lamiaceae has been described as the "Queen of plants" and the "mother medicine of nature"due to its perceived medicinal qualities. [20]

It has been one of the most valued and holistic herbs used over years in traditional medicine in India and almost every part of the plant has been found to possess therapeutic properties.[20]

Traditionally, Tulsi is used in different forms like aqueous extracts from the leaves (fresh or dried as powder), oils extracts; Oils extracted claimed to have numerous useful properties, including as expectorants, analgesics, antiemetics, and antipyretics; stress reducers and inflammation relievers; and as anti-asthmatic, hypoglycemic, hepatoprotective, hypotensive, hypolipidemic, and immunomodulatory agents. [20] In our study Tulsi oil also showed incomplete sterilization of some samples and in microscopic examination it showed enterococcus species. However, contradictory results were noticed in the study by Hugar S et al.[4]and Pradeep Muttagadur Chandrappa et al.[21] that this oil was effective against enterococcus species.

Clove (Syzygiumaromaticum) on the other hand, is a plant widely cultivated in Spice Islands, Indonesia, Pemba and Zanzibar, though earlier production of the plant was in China.[22]The antimicrobial activity of clove is attributable to eugenol, oleic acids and lipids found in its essential oils. [23]

Clove extracts were found to inhibit the growth of Pseudomonas aeruginosa, Candida albicans, Staphylococcus aureus, Salmonella choleraesuis, Klebsiellapneumoniae,[24] but on other hand Arora and Kaur [25] found the aqueous extracts of clove to possess no antimicrobial activity against Pseudomonas aeruginosa, Staphylococcus aureusor Escherichia coli but possessed some activity against Shigellaflexneri. 
In our study clove oil showed insufficient sterilization along with enterococcus bacterial growth. However, contradictory results were noticed in the study by Hugar $\mathrm{S}$ et al.[4] and Anshul Shah et al.[26] that this oil was effective against enterococcus species. It may be due to the change in concentration of oil.

\section{Conclusion:}

Garlic oil can be used as an alternative method to autoclave against aerobic bacteria but Autoclave is the gold standard disinfecting method for sterilization.

\section{References:}

1. Yenni M, Bandi S, Avula SS, Margana PG, Kakarla P, Amrutavalli A. Comparative evaluation of four different sterilization methods on contaminated endodontic files. CHRISMED J Health Res 2017; 4:194-7.

2. Gajan EB, Aghazadeh M, Abashov R, Salem Milani A, Moosavi Z. Microbial flora of root canals of pulpallyinfected teeth: Enterococcus faecalis a prevalent species. J Dent Res Dent Clin Dent Prospects 2009; 3:24-7.

3. Ziauddin S, Bhandary S, Pramod J, Srinivasan R, Mahesh MC. A comparative evaluation of the effectiveness of different cleaning protocols on removal of biological debris on endodontic instruments - An in vitro study. Endodontology 2013;25:19-26.

4. Hugar S, Patel PM, Nagmoti J, UppinC, Mistry L, Dhariwal N. An in vitro Comparative Evaluation of Efficacy of Disinfecting Ability of Garlic Oil, Neem Oil, Clove Oil, and Tulsi Oil with autoclaving on Endodontic $\mathrm{K}$ Files tested against Enterococcus faecalis. Int J ClinPediatr Dent 2017; 10:283-288.

5. Peciuliene V, Maneliene R, Balcikonyte E, Drukteinis S, Rutkunas V. Microorganisms in root canal infections: A review. Stomatologija 2008; 10:4-9.

6. George M, Ivancaková R. Root canal microflora. ActaMedica (Hradec Kralove) 2007; 50:7-15.

7. Matsuura $\mathrm{H}$ et al, Phytochemistry of garlic horticultural and processing procedures. In Nutraceuticals: Designer Foods III Garlic, Soy and Licorice, Lanchance PP (Ed.). Food and Nutrition Press: Trumbell, CT. 1997; 55-69.

8. Athavale VB. New Delhi: Chaukhamba Sanskrit Pratishthan; 1999. Dentistry in Ayurveda Danta-Shastra.

9. Biswas K. Chattopadhyay, Bannerjee RK, Bandopadhyay U. Biological activities and medicinal properties of neem (Azadirachtaindica). Cur Si.2002; 82:1336-1345.
10. Chopra R.N Nayer, S.L and Chopra, I. C., Glossary of Indian Medicinal Plant, CSIR, New Delhi, 1965.

11. Jain A, Basal E. Inhibition of Propionicbacterium acnesinduced mediators of inflammation by Indian herbs. Phytomedicine. 2003; 10:34-38.

12. Okpanyi SN, Ezeukwu GC. Anti-inflammatory and antipyretic activities of Azadirachtaindica. Planta Med. 1981;41:34-9.

13. Pai MR, Acharya LD, Udupa N. Evaluation of antiplaque activity of Azadirachtaindica leaf extract gel - A 6-week clinical study. J Ethnopharmacol. 2004; 90: 99-103.

14. Fabry W, Okemo PO, Ansorg R. Antibacterial activity of East African medicinal plants. J Ethnopharmacol. 1998; 60:79-84.

15. Natarajan V, Pushkala S, Karuppiah VP, Prasad PV. Anti dermatophytic activity of Azardirachtaindica (neem) by in vitro study. Indian J PatholMicrobiol. 2002; 45:311-3.

16. Nwosu MO, Okafor JI. Preliminary studies of the antifungal activities of some medicinal plants against Basidio bolus and some other pathogenic fungi. Mycoses. 1995; 38: 191-5.

17. Upadhyay SN, Dhawan S, Garg S, Talwar GP. Immunomodulatory effects of neem (Azadirachtaindica) oil. Int J Immunopharmacol. 1992;14:1187-93.

18. Dikshita Ray Barua et al., Efficacy of Neem Extract and Three Antimicrobial Agents Incorporated into Tissue Conditioner in Inhibiting the Growth of C. Albicansand S. Mutans.Journal of Clinical and Diagnostic Research. 2017; 11:97-101.

19. Mathela,C.S. "Allelochemicals in medicinal and aromatic plants," in Allelopathy in Agriculture and Forestry, edsS.S.Narwal and P.Tauro (Jodhper: ScientificPublishers), (1991). 213-228.

20. Singh V, Amdekar S, Verma O. Ocimum Sanctum (tulsi): Bio-pharmacological Activities. Webmed central pharmacology 2010; 1: WMC001046 doi: 10.9754/journal.wmc.2010.001046.

21. Pradeep MuttagadurChandrappa, AkashDupper, PragyaTripathi, Ramakrishna Arroju, Preeti Sharma, and Konthoujam Sulochana Antimicrobial activity of herbal medicines (tulsi extract, neem extract) and chlorhexidine against Enterococcus faecalis in Endodontics: An in vitro study. J IntSocPrev Community Dent. 2015; 5: S89-S92.

22. Deans SG, Ritchie GA. Antimicrobial properties of plant essential oils. Int J Food Microbiol 1987; 5: 165- 180.

23. Hammer KA, Carson CF, Riley TV. Antimicrobial Activity of Essential Oils and Other Plant Extracts. J ApplMicrobiol 1999; 86: 985-990. 
University J Dent Scie 2020; Vol. 6, Issue 3

24. Cosentino S, Tubeerso CIG, Pisano B, Satta M, Mascia V, Arzedi E, Palmas F. In-Vitro Antimicrobial Activity and Chemical Composition of Sardinian Thymus Essential Oils. LettApplMicrobiol 1999; 29: 130-135.

25. Hammer KA, Carson CF, Riley TV. Antimicrobial Activity of Essential Oils and Other Plant Extracts. J Appl Microbiol 1999; 86: 985-990.

26. Anshul Shah, MaithileeJani, Harsh Shah, Nisarg Chaudhary, AnujaShah:Antimicrobial Effect of Clove Oil (Laung) Extract on Enterococcus faecalis. Journal of Advanced Oral Research 2014; 5:36-39. 